\title{
ENTREVISTA COM JÚLIA DE CARVALHO \\ HANSEN
}

\section{AN INTERVIEW WITH JÚLIA DE CARVALHO HANSEN}

\author{
Júlia de Carvalho Hansen \\ Entrevista por:
}

SUA OBRA HABITA BRASIL E PORTUGAL, TENDO PUBLICAÇŌES EM AMBOS OS PAÍSES. A APRESENTAÇÃO DA EDIÇÃO PORTUGUESA DE CANTOS DE ESTIMA DIZ: "FOI TANTO DESEJO DE SER LISBOETA OUE AGORA É". DE QUE MODO SE PRESENTIFICAM, EM SEUS PROCESSOS DE ESCRITA, OS RASTROS DESSAS TRAVESSIAS?

Acho que a escrita me interessa por ser um processo semelhante ao das viagens, ou pelo menos das experiências que podem ser vividas em desloca mentos, movimentos, esbarrões e fascínios que acontecem quando diferentes culturas entram em contato. Tenho muito gosto em escrever e gosto enqua nto escrevo de ir sentindo algo parecido com a magia do estranhamento da viagem. Tendo a colocar na perspectiva do poema um território de aventura, em que algo ou tudo pode sair do lugar e, como numa viagem,
* clarissa.xavier3@gmail.com

Clarissa Xavier é mestranda em Estudos Literários pela Universidade Federal de Minas Gerais e editora da revista Em Tese. Pesquisa as topicas relacionadas ao espaço em um estudo comparativo sobre as obras poéticas de Sophia de Mello Breyner Andresen e Ana Martins

quem lê acaba por se sentir mais vivo, com o tempo passando de maneira diferente, como acontece nas (boas) viagens. Tento, dentro da língua que escrevo, produzir esse tipo de travessia, de atravessamento. Ao mesmo tempo, me sinto sempre uma estrangeira observando o corpo do poema conforme ele vai se formando / eu vou escrevendo.

Agora, a apresentação que você cita da edição que a Douda Correria publicou em 2015 do cantos de estima (meu primeiro livro, lançado anteriormente em edição de autora em 2009 em São Paulo) é uma piscada de olhos carinhosa para o passado. Quando o Nuno Moura me convidou para editar esse livro com eles senti como se um ciclo se fechasse com coincidência e sincronia. Isto porque terminei de escrever e publiquei o livro às vésperas da minha mudança de 
residência para Lisboa (que ta mbém aconteceu em 2009). E o cantos de estima fala apaixonadamente do desejo dessa mudança, do encantamento pelas possibilidades de contemplação do ritmo da beleza que Lisboa tem, e também trata do fascínio pelas transformações que conviver com outra variante do português causou na minha vida. Tenho os ouvidos bastante plásticos e mergulhar no convívio com o português de Portugal explodiu minha sintaxe escrita e eu, talvez por ser uma ávida leitora de Roland Barthes, saquei imediatamente que aquilo era um tesouro, um fundamento.

O POEMA “ALFORRIA BLUES" É ABERTO PELOS VERSOS “ESTE LIVRO É INÉDITO/ TIPO A VIDA. QUEM O ESCREVEU/ FUI EU/ QUE SOU O ESPATIFADO DO POSSÍVEL/ CORAÇÃO". A APRESENTAÇÃO DE CANTOS DE ESTIMA, JÁ COMENTADA, AVISA QUE "AS EDIÇÕES APRESENTAM VARIANTES ENTRE SI. NENHUMA SERA DEFINITIVA, EMBORA CADA UMA DELAS SEJA". O QUE GUIA SEU INTERESSE PELA REESCRITA - OU NÃO - DOS POEMAS?

Não alterei muitas coisas entre as reedições dos cantos de estima - só tirei aquilo que considerei que me arrependia de ter publicado. Por sorte me arrependo pouco! Mas mantive sempre muitas coisas que em outros momentos, digamos, em momentos mais atuais, não publicaria nem a pau. Acho que é normal. As questões se deslocam, as visões que fazemos sobre o que fazemos ta mbém e, talvez mais do que isto, é fato: escrever é um treinamento como outro qualquer, quanto mais se faz, acho eu que numa boa mistura entre gozo liberto e rigor crítico, mais perícia se cria. Tento não exigir dos meus textos do passado que eles mostrem a perícia que fui ganhando, até porque precisei deles pra aprender a manejar minimamente efeitos, ritmos e sensações como hoje sei que consigo nos poemas. Respeito e admiro certa ingenuidade anterior e quando algo me incomoda muito tento me lembrar com alguma cândida ironia que o tosco faz parte. Quero dizer com isto que sempre que reviso textos meus já publicados pra novas edições, tento respeitar quem eu era no passado, lembrar que se configurei determinado texto de determinada maneira que hoje já não coincide com o que acho ideal, bem, eu era outra pessoa e gosto de tentar respeitar as outras pessoas.

Já em textos que ainda não foram publicados eu reviso e reescrevo obsessivamente a té sentir que existe algo neles que se move como um bicho vivo. Gosto do gesto de tornar um poema independente de mim, uma espécie de massa de energia que pode causar impacto e vínculo em outro - algo assim. Ao mesmo tempo, é curioso como de repente se cria 
uma estabilidade do objeto, o poema é como um objeto estável cheio de vida na sua instabilidade. Algo que faísca movimento em seu interior conforme alguém se liga a ele. Quando chego a isso aí eu sorrio, me tranquilizo, fico satisfeita pra além do prazer que sinto ao escrever. É outra qualidade de prazer.

Pra chegar a esse ponto fico relendo e relendo em voz alta, reescrevendo, por vezes mudando as mídias de edição, tipo passando o texto da mão pro computador, do computador pra tela do celular, da tela do celular pra máquina de escrever e assim sucessiva mente, sempre tentando retirar qualquer coisa que me incomode ou o olhar, ou os ouvidos, ou a garganta. Sou bastante crítica. Toda minha liberdade é criteriosa. Esse processo de finalização em alguns poemas leva 2 dias, em outros, 2 a nos. Às vezes me encho e devolvo o poema pra matéria escura, apago, esqueço, desencano e quando chego a fazer isso é sem frustração. Muitas vezes deixo de lado, mas desistir ja mais. Resiliência me define. Tenho verdadeira obsessão com a materialidade final dos poemas, preciso vê-los feitos em livros e isto me norteia bastante o conseguir finalizá-los. Leve o tempo que for Olhando pra trás, a té que sou rápida, mas me sinto demoradíssima. Pra terminar o Romã passei cerca de 1 a no só fazendo revisões e montagens com os poemas que vieram a ser publicados no livro, sem escrever nada de "novo".

PARA VOCÊ, ONDE UM LIVRO DE POEMAS, QUE A CADA INSTANTE É INÉDITO (ATUALIZADO PELA REINVENÇÃO DA VIDA), SITUA O AUTOR E O LEITOR QUE O ACOMPANHA?

Nossa, que pergunta difícil - acho que porque não existe "o leitor". O leitor é uma espécie de holograma, de específico, de singular. Acho que um bom livro de poemas situa em si quem o lê. É um tipo de espelho, mas um espelho sinestésico e imagina tivo, porque é como se quem lê se visse num espelho, mas com uma paisagem totalmente diferente, outras rugas se formando, como se a re-situação da leitura de um bom poema fosse ta mbém uma desterritorialização, um canal de magma tectônico, outro foco pra olhar através da língua, através de si. É um salto, um sopro, um sobrevôo. É como se acontecesse uma presentificação do estranhamento que se reconhece. Algo por aí. Lembro também de uma coisa que meu pai sempre fala sobre a literatura e que eu concordo definitivamente: é que é a literatura que nos lê, e não o contrário.

OS VERSOS QUE ABREM O QUINTO POEMA DE SEIVA, VENENO OU FRUTO DIZEM: “OS LIVROS SÃO DE NATUREZA MINERAL./ 
ALGUNS BEBEM-SE OUTROS SE PROLIFERAM/ COMO ÁGUA. OU TROS PEDRA, NÃO FRUTA/ ROCHA DE ONDE BROTA A TUA PELE". ESSE LIVRO, QUE DEMANDA UMA ATENÇÃO A TUDO O QUE SE VÊ NA TERRA, PRATICA, AO MESMO TEMPO, A CAPACIDADE DE EXPANSÃO DO OUE É VISTO. COMO A SUA POESIA SE RELACIONA COM A TAREFA DE ESTAR NO MUNDO E A HABILIDADE DE VÊ-LO?

Não sei muito bem porque essa obsessão com o ver apareceu no Seiva veneno ou fruto. Talvez ver seja o verbo desse livro. Biograficamente isso teve a ver com o SVF ter sido escrito durante uma fase em que com mais recorrência tomei ayahuasca na vida. Através dos processos das visões sinestésicas da ayahuasca, isto é, das visões que você tem com o corpo todo, eu aprendi muitas coisas a respeito de mim mesma e ta mbém ganhei uma cosmovisão, uma espécie de compreensão mais integrada das relações entre as coisas todas e os seres que são vivos no mundo, coisa que certamente os povos indígenas mantém e têm no mundo

Também acho que me interessa no "ver" uma dupla articulação entre imaginário e real que a visão carrega. Como se a visão fosse uma intermediadora, uma interpretação do sensível. Me interessa o fato de que a visão pode vir da miragem, da imaginação, do inconsciente que sonha, do sopro dos anjos, da premonição do futuro, da aproximação das entidades, dos caminhos mediúnicos, da loucura, das substâncias expansoras de consciência, etc - essas coisas que meu ascendente em Peixes tem fascínio. Mas, ao mesmo tempo, a visão também está fortemente determinada pelo relacionamento com o material, o tangível, o reconhecível no limite como o real. A visão é muitas vezes a significadora da realidade. Então eu acho que a visão faz uma espécie de campo de mediação entre o visível e o invisível - e tudo que está no meio, na mídia, no que faz transporte. Tudo que está entre dimensões me interessa buscar, revelar, permear. Um dos primeiros versos do Seiva diz "como gostaria de ver o poder ver". Eu adoro esse verso porque nunca sei direito o que quis dizer com isto. Como se residisse na visão um mistério de potência, um filtro de algo que está por trás - e que, talvez, como todo mistério, dorme com tranquilidade e pode ser deflagrado numa explosão a qualquer momento.

Me lembro também de uma deidade budista que é a Tara Branca, uma deidade feminina ligada à compaixão Ela tem 7 olhos distribuídos pelo corpo todo; além dos 2 que temos, tem o terceiro olho no meio da testa e um olho em cada palma das e dos pés. A ideia é um tanto de que a compaixão observa as coisas com muitos olhos, de muitos pontos de vista. 
Não me interessa em nada a ideia de buscar iluminação. Sou uma pessoa cheia de vícios - os cultivo com prazer, inclusive, mas certa mente me interessa buscar saúde emocional, coisa com a qual não nasci com disponibilidade. Hoje em dia, quando falo isso, as pessoas não acreditam, mas sou centralmente uma pessoa auto-destrutiva. Lido com isso há décadas. Penso que comecei a lidar com isto quando entrei com 17 a nos de idade no consultório do meu (ex-)psica nalista lacaniano. Desde então, se enumerasse os tipos de terapias, retiros, oráculos e afins pelos quais já passei, preencheria pelo menos meia la uda. Imagino que perto de morrer poderei escrever uma lista telefônica a respeito e, sobretudo, não terei me matado. Não ter me matado talvez seja a maior vitória da minha vida. Então, com o passar do tempo nesse trabalho hercúleo de auto-conhecimento, venho mesmo percebendo que conseguir arejar os pontos de vista do que se vê pode ajudar muito no a mor, na leveza, na paciência, na cordialidade, no bom humor - essas qualidades que me interessam envelhecer com.

EM ROMÃ, A TÓPICA AMOROSA - TÃO ANTIGA QUANTO A POESIA - SE TORNA TAMBÉM INÉDITA. HÁ NESSE LIVRO UMA CHAMADA PARA O DIÁLOGO ENTRE AQUELES QUE SE INSCREVEM COMO O EU E O OUTRO, AFINAL, SÃO POEMAS DE AMOR. MAS
HÁ TAMBÉM OUTROS PROCESSOS QUE ATRAVESSAM ESSE PERCURSO ATEMPORAL DA TÓPICA E TRANSFORMAM OS SUJEITOS EM HABITANTES DE UM TEMPO-ESPAÇO DEMARCADO, COMO NOS VERSOS DE "POSSO": "POSSO INVENTAR-NOS UM DESFECHO/ TE CHAMAR DE ILHA, CHARCO/ TRAVESSIA/ ESOUECER EU NÃO POSSO - POSSO/ DIZER QUE EU IREI ME LEMBRAR.// POSSO PERGUNTAR PELO TEMPO/E ASSIM CONVERSAREMOS SOBRE O BREU/ NORMATIVO E INCONSTITUCIONAL DESSES DIAS/ E DE COMO NÃO SEREMOS DERROTADOS.// UM PELO OUTRO, TALVEZ, NÃO." O POEMA, ASSIM, TRANSFORMA OS NOMES DO AMOR EM IMAGENS ESPACIAIS E NARRATIVAS. EM SUA ESCRITA, O QUE CONDUZ A PRESENÇA E AS TRANSFORMAÇÕES DO TEMA AMOROSO?

Pela mordedeusa o que conduz essa presença é algum capeta dos infernos, porque peloa mor que obsessão, alguém me livre. Deve ser tesão, desejo, e foi só a gente falar nessas coisas que me lembrei de citar Lulu Santos cantando "será magia miragem milagre? será mistério". Eu acho isso: que o registro a moroso é um registro de domínio pop, isto é, traz uma espécie de carga de ligação que conecta em qualquer um. Sei lá, você está sentada num bar, ou num café e começa a tocar uma música que te lembra alguém que você a mou, ou você está espera ndo o tempo passar e começa a prestar atenção na música que está tocando lá no fundo. 
Acho que se ela falar de amor a chance de você criar alguma relação com ela, seja de prazer, seja de riso, é duzentas vezes maior do que se for uma música sobre sei lá o quê.

Quando num poema de amor alguém lê "você", imediatamente o pivô da língua se realoca. Você imagina alguém naquele destinatário, ou se coloca como o destina tá rio daquela mensagem. É como se o poema de amor habitasse com intensidade os usos pronominais da língua e o fato de que eles podem ser possessivos, identitários, etc., faz com que os pronomes pessoais esteja m bastante rentes ao sujeito. Me interessou no Romã não só produzir os efeitos diretos disto, como por vezes demonstrar, pra um leitor mais atento, que isto está acontecendo nas operações da linguagem que o texto media tiza, que o texto tem ta mbém consciência de si.

No mais, qua ndo terminei o Seiva veneno ou fruto eu sentia que tinha chegado a um ponto de cristalização da es crita que procurava desde os meus 13 anos de idade quando li o Alguma Poesia do Drummond e decidi que queria escrever poemas ta mbém. Some-se a isto o fato de que o SVF foi meu terceiro livro publicado, mas o primeiro a encontrar uma rede a mpla de leitores, o que também quer dizer que depois dele eu sentia certa expectativa do público leitor, ou do meu imaginário de um público leitor, às vezes mais a migável, às vezes mais ressentido. Infelizmente, tem muita gente que torce pra gente se fuder com os holofotes em cima, mas as expectativas positivas são por vezes até mais sufocantes de se lidar.

Eu tinha feito uma escolha ao montar o Seiva de que não queria ter poemas de amor, de dedicação do gesto a moroso no livro. Lembro de pensar mais rigidamente que não queria que fosse presente a facilitação da interlocução do gesto a moroso naquele livro afiado e cortante que é o SVF. Me interessava mais a interlocução com o outrem do que com o outro. Antes dialogar com a morte, as plantas, os deuses, os a nimais, do que com o outro humano. Por que eu quis isto não sei.

Em resumo: como resposta a uma sensação de esgotamento que tive ao terminar o Seiva veneno ou fruto sent que a única potência que poderia se colocar com tanta ou mais intensidade seria o poema a moroso. Escolhi deliberadamente trabalhar com um tema que me parecesse viável e inesgotável. Talvez nada me interesse individualmente mais na vida do que o desejo, o tesão, a paixão. Sofro muito por a mor ou por algo que acredito sê-lo. Ao mesmo tempo, isto pode ser funcional, porque desde que a poesia é poesia 


\section{9}

a tópica amorosa tem potências a se recriar infinitamente. Foi a primeira vez que escolhi conscientemente trabalhar um tema num livro e isso foi muito interessante, porque ta mbém se mostrou inesgotável. A gente sabe que tudo já foi feito em termos de literatura, mas é isto ta mbém que torna a literatura inesgotável.

DITO ISSO, EM SUA PERSPECTIVA, ONDE RESIDE A POTÊNCIA DA POESIA?

Não sei, mas procuro por isso. 